\title{
The expression of C-FABP and PPAR $\gamma$ and their prognostic significance in prostate cancer
}

\author{
FARZAD S. FOROOTAN ${ }^{1}$, SHIVA S. FOROOTAN ${ }^{1}$, MOHAMMED I. MALKI $^{1}$, DANQING CHEN ${ }^{1}$, \\ GANDI LI ${ }^{3}, \mathrm{KELIN}^{1}$, PHILIP S. RUDLAND ${ }^{2}$, CHRISTOPHER S. FOSTER ${ }^{1}$ and YOUQIANG KE ${ }^{1}$ \\ ${ }^{1}$ Molecular Pathology Laboratory, Department of Molecular and Clinical Cancer Medicine, ${ }^{2}$ Department of Biochemistry \\ and Cell Biology, Liverpool University, Liverpool, L69 3GA, UK; ${ }^{3}$ Department of Pathology, \\ West-China Hospital/West-China Medical School, Sichuan University, P.R. China
}

Received September 14, 2013; Accepted October 17, 2013

DOI: $10.3892 /$ ijo.2013.2166

\begin{abstract}
The purpose of this study was to test the hypothesis that cooperative interaction between cutaneous fatty acid-binding protein (C-FABP) and peroxisome proliferator-activated receptors (PPAR) promotes the malignant progression of human prostate cancer. The expression of C-FABP, PPAR $\beta / \delta$ and PPAR $\gamma$ was measured by western blot analysis in prostate cell lines and by immunohistochemical staining in tissue sections of benign prostatic hyperplasia (BPH) and prostatic carcinomas. The correlation between the expression of PPARs and C-FABP was assessed. The significance of increased expression of these proteins was analysed with respect to prognosis and compared with those of alternative biomarkers. The expression levels of C-FABP and PPAR $\gamma$ in prostate cancer cell lines and the cytoplasm and nuclei of carcinoma tissues were significantly (Student's t-test, $\mathrm{p}<0.05$ ) higher compared to those in benign cell lines and BPH tissues. The raised expression level of C-FABP and PPAR $\gamma$ was significantly correlated with the increased combined Gleason scores (GS) of the carcinomas. Enhanced expression of cytoplasmic C-FABP significantly correlated with increased nuclear PPAR $\gamma($ Student's t-test, $\mathrm{p}<0.005)$. While expression of PPAR $\beta / \delta$ in carcinomas did not correlate with patient outcome, the increased levels of both C-FABP and PPAR $\gamma$ were associated with shorter patient survival. Multivariate analysis indicated that C-FABP was independently associated with patient survival, whereas PPAR $\gamma$ was confounded by C-FABP in predicting patient survival. Thus, the increased C-FABP may interact with PPAR $\gamma$ in a coordinated mechanism to facilitate malignant progression in prostatic cancer.
\end{abstract}

Correspondence to: Professor Youqiang Ke, Molecular Pathology Laboratory, Department of Molecular and Clinical Cancer Medicine, The University of Liverpool, 5/6 Floor, Duncan Building, Daulby Street, Liverpool L69 3GA, UK

E-mail: yqk@liverpool.ac.uk

Key words: prostate cancer, C-FABP, PPAR $\gamma, \operatorname{PPAR} \beta / \delta$, prognostic factor
Both C-FABP and PPAR $\gamma$ are suitable as prognostic factors to predict the clinical outcome of prostatic cancer patients.

\section{Introduction}

Prostate cancer is the most common male malignant disease and the second leading cause of male cancer death in developed countries (1). Although current treatment strategies based on androgen ablation can produce very effective initial results, the majority of cases relapse in $<2$ years with a more aggressive hormone independent form (2). Currently, there is no curative treatment for androgen-independent prostate cancer. Development of more effective treatment strategies, particularly for androgen-independent cancer, relies on understanding further the molecular mechanisms responsible for malignant progression. Thus, identification of cancer-related genes and understanding how these genes function inside cancer cells to promote or to suppress tumorigenicity are important initial steps for either better diagnosis or prognosis and for the identification of better therapeutic targets in the future.

The gene $C-F A B P$, also named $F A B P 5, P A-F A B P$ and $E-F A B P$, encodes a small cytosolic protein, initially identified in skin (3). When the gene $C-F A B P$ was first discovered to be overexpressed in prostate cancer cells, it was demonstrated to induce metastasis when rat benign R37 model cells were transfected with its expression vector and transplanted into syngeneic rats $(4,5)$. Forced expression of C-FABP in the weakly malignant prostate cancer cell line LNCaP, which did not express $C-F A B P$ prior to transfection, exhibited significantly increased tumorigenicity of gene-recipient cells both in vitro and in vivo (6). Conversely, suppression of $C-F A B P$ expression in the highly malignant prostate cancer cell line PC3M reduced its tumorigenicity in vivo and in vivo (7-9). However, molecular mechanisms involved in its cancer-promoting activity are not fully understood. Since an important activity of C-FABP is to bind and transport intracellular fatty acids into cells (3), its cancer-promoting activity may be related to its fatty acid-binding function or to an alternative, hitherto undefined function. A precedent for such a proposition is found in several different roles of succinate dehydrogenase (10). Not only are fatty acids important energy sources, they are also signalling molecules in their own right $(11,12)$ that may stimulate their 
nuclear receptor PPARs which are ligand specific transcription factors (13). Thus it was hypothesized that the increased C-FABP may transport large amount of intracellular fatty acids into cancer cells to activate their nuclear peroxisome proliferative-activated receptors (PPARs) which may then activate the downstream cancer-promoting genes $(6,7)$. PPARs are transcription factors that bind to DNA and regulate transcription in a ligand-dependent manner $(14,15)$. PPARs consist of 3 main subtypes: PPAR $\alpha$ (NR1C1), PPAR $\beta$ (also called PPARס, NUC1 and FAAR) and PPAR $\gamma$ (NR1C3). PPAR $\alpha$ is highly expressed in tissues with a high rate of mitochondrial fatty acid oxidation, such as liver, muscle, heart, kidney and cells of arterial walls $(16,17)$. PPAR $\alpha$ regulates expression of the genes involved in lipoprotein metabolism and thus raises the level of apolipoprotein. PPAR $\beta / \delta$ is found in most tissues and is only weakly activated by fatty acids (18). Recently, PPAR $\beta / \delta$ was shown to be expressed in cancers of many different organs, including lung, prostate, bladder, colon, breast, duodenum, thyroid and may play a key role in their carcinogenesis (19). PPAR $\gamma$ which is highly expressed in adipose tissues is a critical regulator of adipocyte differentiation and is implicated in a variety of neoplastic processes (20). PPAR $\alpha$ is unlikely to be related to the biological activity of C-FABP, since it is not expressed in prostate (21). Thus possible receptors receiving fatty acids delivered by C-FABP could be either PPAR $\beta / \delta$ or PPAR $\gamma$, or both of them.

To identify how the proposed $C$ - $F A B P$-PPAR axis exerts cancer-promoting activity, we first assessed the expression of C-FABP, PPAR $\beta / \delta$ and PPAR $\gamma$ in a series of benign and malignant prostatic epithelial cell lines and in an archival set of well-characterised benign and malignant prostate tissues. The relationship between the increased expression of these three proteins and the grade of malignancy within the tissues and patient survival was assessed. The prognostic significance of these factors (individually and jointly) on patient outcome was analysed and compared with those factors currently in use.

\section{Materials and methods}

Cell lines and culture conditions. The following five human prostate epithelial cell lines were used in this study: benign prostate epithelial cell line PNT2 $(22,23)$, weakly malignant cell line LNCaP (24), highly malignant cell lines DU145 (25), PC3 (26) and PC3M which was derived from the most malignant metastatic population of PC3 (27). Cells were cultured and maintained in RPMI-1640 medium (Invitrogen, Paisley, UK) supplemented with 10\% (v/v) FCS (Biosera, East Sussex, UK), penicillin $(100 \mathrm{U} / \mathrm{ml})$ and stereptomycin $(100 \mu \mathrm{g} /$ $\mathrm{ml})$ (Invitrogen). Sodium pyruvate $(100 \mu \mathrm{g} / \mathrm{ml})$ (Sigma, Grillingham, UK) was added into the culture medium of LNCaP cells.

Tissue samples and patient data. Human prostate tissues, the same as those used in our previous studies (28-31), were selected from an archival set with follow-up data held in Department of Molecular and Clinical Cancer Medicine (originally named Department of Pathology), University of Liverpool, UK. Patients who were originally diagnosed with prostate cancer, but who died from other causes were excluded. Tissues were taken from 35 benign prostatic hyperplasia
(BPH) patients and from 97 prostate adenocarcinoma patients with an average age of 67.5 and 73 years, respectively. All patients studied were treated by trans-urethral resection of the prostate (TURP) in the Royal Liverpool University Hospital between 1995 and 2001. Since all tissue samples were kept anonymously and most of the patients have passed away, our local NHS ethics committee waived the need for consent. This study was approved by the National Science Ethics Committee in accordance with the Medical Research Council guidelines (project reference number: Ke; 02/019). Specimens had been fixed in $10 \%$ (v/o) formalin and embedded in paraffin wax. Cut histological sections were examined independently by two qualified pathologists and classified as BPH and carcinomas and further classified according to their combined Gleason scores (GS) (32).

Western blotting. Levels of C-FABP, PPAR $\beta / \delta$ and PPAR $\gamma$ in prostate cell lines was detected by western blot analysis using an ECL detection system $(29,33)$. The blot was first incubated with a primary antibody, which was either anti-human C-FABP rabbit polyclonal antibody (Hycolt Biotech; HP-9030; 1:500 dilution), anti-PPAR $\beta / \delta$ rabbit polyclonal antibody (Thermo; A1-86845; 1:1,000 dilution) or anti-PPAR $\gamma$ rabbit polyclonal antibody (Santa Cruz; SC-7196; 1:100 dilution), then incubated with secondary antibody, swine anti-rabbit IgG (Dako; 1:10,000 dilution) conjugated with horseradish peroxidase. Antibody-bound proteins were visualized by exposure to Kodak XAR-5 film at room temperature. Sizes of the bands were quantified by measuring the intensity of peak areas using an Alpha Imager 2000 densitometer (Alpha Innotech, Cannock, UK). The same blots were incubated with anti- $\beta$ actin antibody to correct for possible loading discrepancies.

Histological and immunohistochemical staining. Histological sections $(4-\mu \mathrm{m})$ were cut from formalin-fixed paraffinembedded tissues $(29,34)$, incubated at $37^{\circ} \mathrm{C}$ overnight, deparaffinised with xylene and stained with hematoxylin and eosin with an automated Varistain 24-4 machine (Thermo Scientific, USA). For immunohistochemical staining, tissue sections were deparaffinised and rehydrated in xylene and ethanol, respectively and then incubated in methanol and hydrogen peroxide $(3 \% \mathrm{v} / \mathrm{v})$ for $12 \mathrm{~min}$ before being washed (28). Immunohistochemical staining was performed with the following commercial antibodies at the stated dilution: antirabbit polyclonal antibody against C-FABP (HP-9030, Hycolt Biotech, The Netherlands), 1:500; anti-goat polyclonal antibody against PPAR $\beta / \delta$ (SC-1987, Santa Cruz Biotechnology Inc.; Santa Cruz, CA, USA), 1:100; anti-goat polyclonal antibody against PPAR $\gamma$ (SC-1984, Santa Cruz Biotechnology Inc.), 1:50; and monoclonal anti-human antibody against androgen receptor (AR) (Dako Ltd., Ely, UK), 1:100. Sections were incubated with C-FABP antibody and AR antibody at room temperature for $1 \mathrm{~h}$ and with PPAR $\beta / \delta$ and PPAR $\gamma$ antibodies in a humid chamber at $4^{\circ} \mathrm{C}$ overnight. Sections were then incubated with a rabbit anti-goat IgG linker (Vector Laboratories, Burlingame, CA, USA) for $30 \mathrm{~min}$. Bound antibodies were detected by incubation with $200 \mu 1$ of EnVision FLEX/HRP (Dakocytomation, Ely, UK) for $30 \mathrm{~min}$ and visualized with DAB (3-3'-diamonobenzidine) for $10 \mathrm{~min}$. All sections were counterstained with hematoxylin and mounted 
A

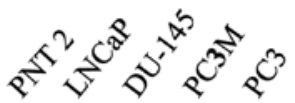

$\operatorname{PPAR} \beta \delta$

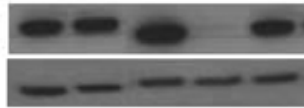

$49 \mathrm{kDa}$

$42 \mathrm{kDa}$
C

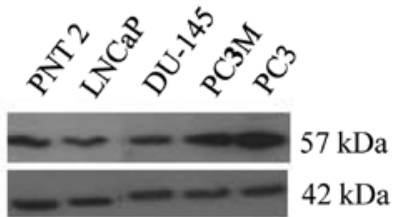

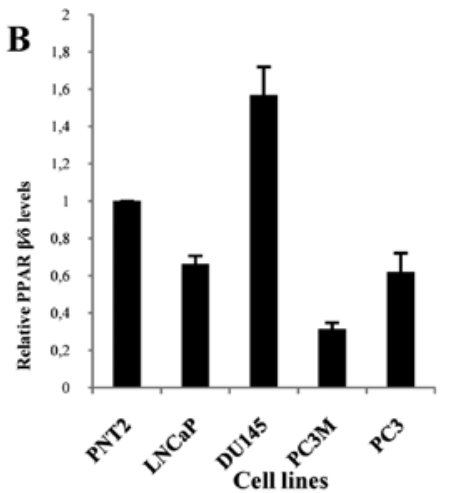
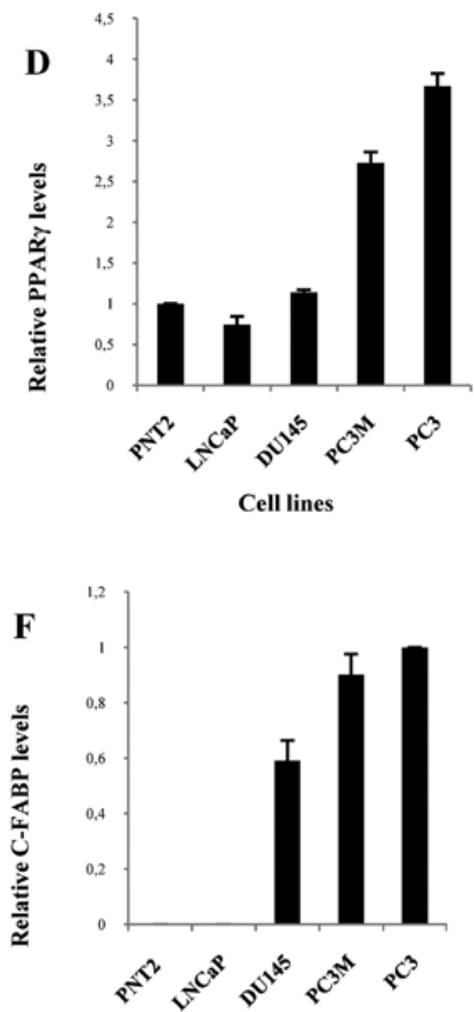

$\mathbf{E}$

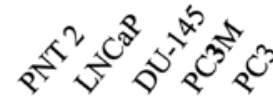

C-FABP

$\beta$-actin

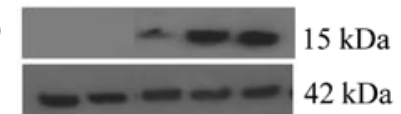

$15 \mathrm{kDa}$

Figure 1. Measurement of levels of C-FABP and its possible nuclear receptors (PPAR $\beta / \delta$ and PPAR $\gamma$ ) in prostate cell lines. Levels of total PPAR $\beta / \delta$ (A), $\operatorname{PPAR} \gamma(\mathrm{C})$ and C-FABP (E) were detected by western blot analysis. To standardize the immune reactions, the same blot was incubated with an anti- $\beta$-actin antibody. Relative levels of each protein [(B) PPAR $\beta / \delta$; (D) PPAR $\gamma$; and (F) C-FABP)] were measured by densitometric scanning the intensities of the relevant protein bands and normalized to that of actin on the same blot. In (B and D), the level of immunoreactive-proteins in PNT2 was set at 1; levels expressed in other cell lines were obtained by comparison with that in PNT2. In (F), the level of immunoreactive-proteins in PC3 was set at 1; levels expressed in other cell lines were obtained by comparison with that in PC3. Results (mean \pm SD) were obtained from 3 separate experiments.

with dibutyl phthalate xylene (DPX). One prostate cancer with GS 10, a benign colon tissue and an oral squamous epithelium were used as a positive control for C-FABP, PPAR $\beta / \delta$, PPAR $\gamma$ antibodies, respectively.

Scoring immunoreactivity. Evaluation of C-FABP, AR, PPAR $\beta / \delta$ and PPAR $\gamma$ immunoreactivity was performed in high power fields (x400) using a standard light microscope. Cytoplasmic and nuclear immunoreactivities were independently reviewed by two separate observers. Cytoplasmic staining was classified into 4 categories according to the intensities: unstained, weakly, moderately and strongly stained which were expressed as $0(-), 1(+), 2(++)$ and $3(+++)$, respectively. Nuclear staining was first assessed by the number of stained nuclei to obtain a percentage score which was $1(\leq 30)$, 2 (31-60), or 3 ( $\geq 61)$; then by the intensity of staining to obtain an intensity score which was $1(+), 2(++)$, or $3(+++)$. The staining index or final scores for nuclear staining was obtained by multiplying the percentage score and intensity score. The final nuclear stains, which scored from 1 to 9 , were further classified into 3 groups: weakly positive (1-3), moderately positive (4-6) and strongly positive (7-9), as described previously (35). The differences in scoring categories between 2 observers were $<5 \%$ of the samples. 


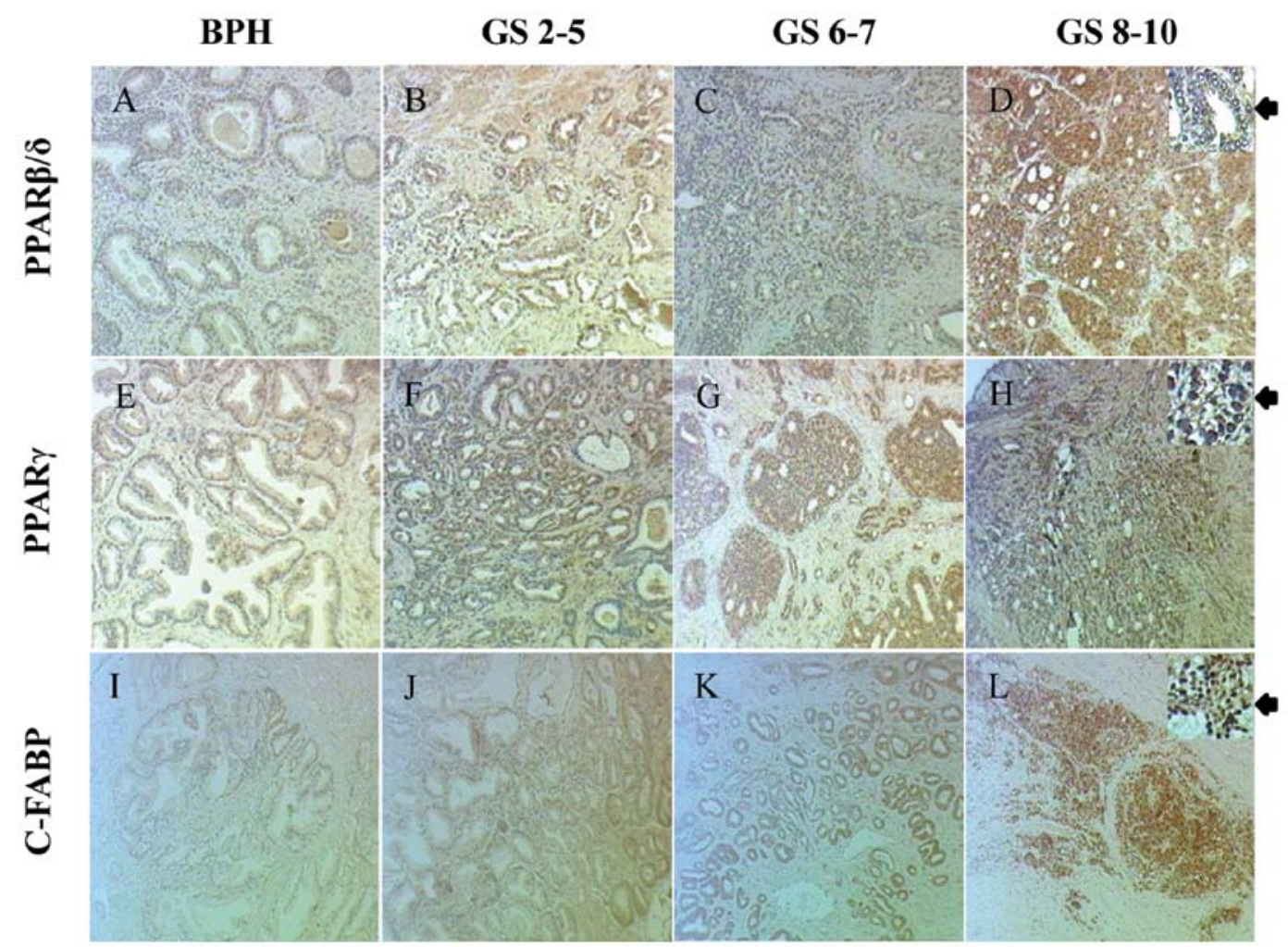

Figure 2. Immunohistochemical staining of BPH and prostatic carcinoma tissues with antibodies against PPAR $\beta / \delta$, PPAR $\gamma$ and C-FABP. Carcinoma tissues were divided into weakly (GS $\leq 5$ ), moderately (GS 6-7) and highly (GS 8-10) malignant groups according to their combined Gleason scores (GS). Cytoplasmic and nuclear stain locations are shown in the inserts (arrows). Original magnifications of images of representative slides were x100; original magnifications of the inserts were $\mathrm{x} 250$.

Statistical analysis. Statistical analysis was performed using the Statistical Package for Social Sciences (SPSS), version 20 (SPSS Inc., Chicago, IL, USA). Correlation between PPAR $\beta / \delta$ and PPAR $\gamma, \mathrm{C}$-FABP and AR expression and the nature of prostate tissue (benign or malignant) were assessed by 2 -sided Fisher's exact test and $\chi^{2}$ analysis. Correlation between survival and expression of individual factors was plotted as KaplanMeier survival curves and significance of their difference was analysed by log-rank test. Cox's multiple regression was used for analysis of the effect of multiple factors on patient survival. In all statistical analyses, results were regarded as significant when $\mathrm{p}<0.05$.

\section{Results}

Detection of PPAR $\beta / \delta, P P A R \gamma$ and C-FABPin prostatic cell lines. Western blots showed that a single PPAR $\beta / \delta$ band of $52 \mathrm{kDa}$ was detected in benign PNT2 cells, weakly malignant LNCaP cells, and highly malignant PC 3 and DU145 cells, but was barely detectable in the highly malignant PC3M cells (Fig. 1A). A single PPAR $\gamma$ band of $57 \mathrm{kDa}$ was detected in all 5 cell lines (Fig. 1C). In contrast C-FABP expression was not detected in benign PNT2 and weakly malignant $\mathrm{LNCaP}$ cells, but a strong $15 \mathrm{kDa}$ C-FABP band was detected in highly malignant cell lines DU145, PC3M and PC3 cells (Fig. 1E). When the densitometric level of PPAR $\beta / \delta$ in PNT2 was set at 1 (Fig. 1B), the level in weakly malignant LNCaP cells was $0.66 \pm 0.04$; levels in highly malignant DU145, PC3M and PC3 cells were $1.57 \pm 0.15,0.31 \pm 0.03$ and $0.61 \pm 0.1$, respectively. The changes in levels of PPAR $\beta / \delta$ did not appear to be related to changes in malignant characteristics. However, a very different pattern was observed in PPAR $\gamma$ levels in these cell lines. When the level of PPAR $\gamma$ in PNT2 was set at 1 (Fig. 1D), the level in weakly malignant $\mathrm{LNCaP}$ cells was $0.74 \pm 0.09$; levels in highly malignant DU145, PC3M and PC 3 cells were $1.14 \pm 0.16$, $2.73 \pm 0.28$ and $3.66 \pm 0.23$, respectively. Thus the level of PPAR $\gamma$ increased with increasing malignancy in these prostatic cells. A similar pattern of C-FABP expression was detected. When the level of C-FABP in PC3 was set at 1 (Fig. 1F), levels expressed in other malignant PC3M and DU145 were reduced to $0.9 \pm 0.07$ and $0.59 \pm 0.07$, respectively. In contrast levels in the benign PNT2 and weakly malignant LNCaP cells were not detectable.

Detection of PPAR $\beta / \delta, P P A R \gamma$ and $C-F A B P$ in prostate tissues. Staining for PPAR $\beta / \delta$ in BPH and carcinomas was detected in both cytoplasm and nucleus (Fig. 2AD) (Table IA). Among 32 stained BPH cases, $28(88 \%)$ were stained weakly and $4(12 \%)$ moderately positive in both cytoplasm and nucleus (Fig. 2A). Among 94 stained adenocarcinoma cases, both cytoplasmic and nuclear staining was observed. Cytoplasmic staining was weak in $32(34 \%)$, moderate in $50(53 \%)$ and strong in $12(13 \%)$ cases and in the nucleus, staining was weak in $13(14 \%)$, moderate in $65(69 \%)$ and strong in $16(17 \%)$ cases (Fig. 2B-D). The levels of both cytoplasmic ( $\chi^{2}$ test, $\mathrm{p}<0.001)$ and nuclear $\left(\chi^{2}\right.$ test, $\left.\mathrm{p}<0.001\right)$ staining for PPAR $\beta / \delta$ were significantly higher in carcinomas than those in $\mathrm{BPH}$ (Table IA). 
Table I. Cytoplasmic and nuclear expression of different PPARs in benign and malignant prostate tissues.

A, PPAR $\beta / \delta$ stain

\begin{tabular}{|c|c|c|c|c|c|c|c|}
\hline \multicolumn{4}{|c|}{ Cytoplasmic stain intensities } & \multirow[b]{2}{*}{ No. of cases } & \multicolumn{3}{|c|}{$\begin{array}{l}\text { Nuclear stain intensity and } \\
\text { percentage score }\end{array}$} \\
\hline Tissues & + & ++ & +++ & & $\leq 3$ & $4-6$ & $\geq 7$ \\
\hline $\mathrm{BPH}$ & 28 & 4 & 0 & $32^{\mathrm{a}}$ & 28 & 4 & 0 \\
\hline Carcinomas (total) & 32 & 50 & 12 & $94^{\mathrm{a}}$ & 13 & 65 & 16 \\
\hline Scores $^{b} \leq 5$ & 6 & 6 & 2 & 14 & 4 & 9 & 3 \\
\hline Scores $^{b}$ 6-7 & 12 & 18 & 5 & 35 & 5 & 25 & 5 \\
\hline Scores $^{b} 8-10$ & 14 & 26 & 5 & 45 & 6 & 31 & 8 \\
\hline
\end{tabular}

$\mathrm{B}, \mathrm{PPAR} \gamma$ stain

Cytoplasmic stain intensities

\begin{tabular}{|c|c|c|c|c|c|c|c|}
\hline Tissues & + & ++ & +++ & No. of cases & $\leq 3$ & $4-6$ & $\geq 7$ \\
\hline $\mathrm{BPH}$ & 31 & 1 & 0 & $32^{\mathrm{a}}$ & 30 & 2 & 0 \\
\hline Carcinomas (total) & 35 & 45 & 10 & $90^{\mathrm{a}}$ & 12 & 57 & 21 \\
\hline Scores $^{b} \leq 5$ & 5 & 7 & 1 & 13 & 4 & 8 & 1 \\
\hline Scores $^{b}$ 6-7 & 13 & 18 & 3 & 34 & 4 & 21 & 9 \\
\hline Scores $^{\mathrm{b}} 8-10$ & 17 & 20 & 6 & 43 & 4 & 28 & 11 \\
\hline
\end{tabular}

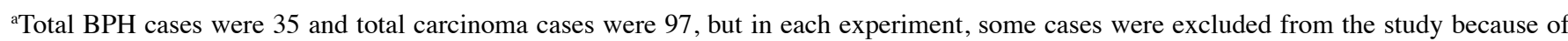
technical reasons. ${ }^{\text {bC }}$ ombine Gleason scores.

Table II. C-FABP cytoplasmic and nuclear expression in benign and malignant prostate tissues.

\begin{tabular}{|c|c|c|c|c|c|c|c|c|c|}
\hline \multicolumn{5}{|c|}{ Cytoplasmic stain intensities } & \multirow[b]{2}{*}{ No. of cases } & \multicolumn{4}{|c|}{$\begin{array}{l}\text { Nuclear stain intensity and } \\
\text { percentage score }\end{array}$} \\
\hline Tissues & 0 & + & ++ & +++ & & 0 & + & ++ & +++ \\
\hline $\mathrm{BPH}$ & 33 & 2 & 0 & 0 & 35 & 25 & 7 & 5 & 3 \\
\hline $\begin{array}{l}\text { Carcinomas } \\
\text { (total) }\end{array}$ & 3 & 23 & 54 & 17 & 97 & 9 & 20 & 32 & 36 \\
\hline Scores $^{\mathrm{a}} \leq 5$ & 2 & 8 & 5 & 1 & 16 & 2 & 6 & 4 & 4 \\
\hline Scores $^{\text {a }}$ 6-7 & 0 & 12 & 17 & 8 & 37 & 4 & 7 & 12 & 14 \\
\hline Scores $^{\text {a }} 8-10$ & 1 & 3 & 32 & 8 & 44 & 3 & 7 & 16 & 18 \\
\hline
\end{tabular}

${ }^{a}$ Combined Gleason scores.

Staining for PPAR $\gamma$ was detected in both cytoplasm and nucleus of cells in BPH and carcinoma tissues (Fig. 2E-H and Table IB). In 32 analysed BPH samples, 31 (97\%) stained weakly and 1 (3\%) stained moderately in the cytoplasm; $30(94 \%)$ stained weakly and $2(6 \%)$ stained moderately in the nucleus (Fig. 2E). Among a total of 90 stained carcinomas, $35(39 \%)$ stained weakly, $45(50 \%)$ stained moderately and $10(11 \%)$ stained strongly in the cytoplasm; $12(13 \%)$ stained weakly, 57 (63\%) stained moderately and 21 (24\%) stained strongly in the nucleus (Fig. 2F-H). Staining for PPAR $\gamma$ in both cytoplasm $\left(\chi^{2}\right.$ test, $\left.\mathrm{p}<0.001\right)$ and nucleus $\left(\chi^{2}\right.$ test, $\left.\mathrm{p}<0.001\right)$ of carcinomas was significantly higher than those in BPH (Table IB).

Immunohistochemical staining for C-FABP was observed in both cytoplasm and nucleus of BPH and carcinoma cells (Fig. 2I-L) (Table II). Among 35 BPH cases, 33 (94\%) were 

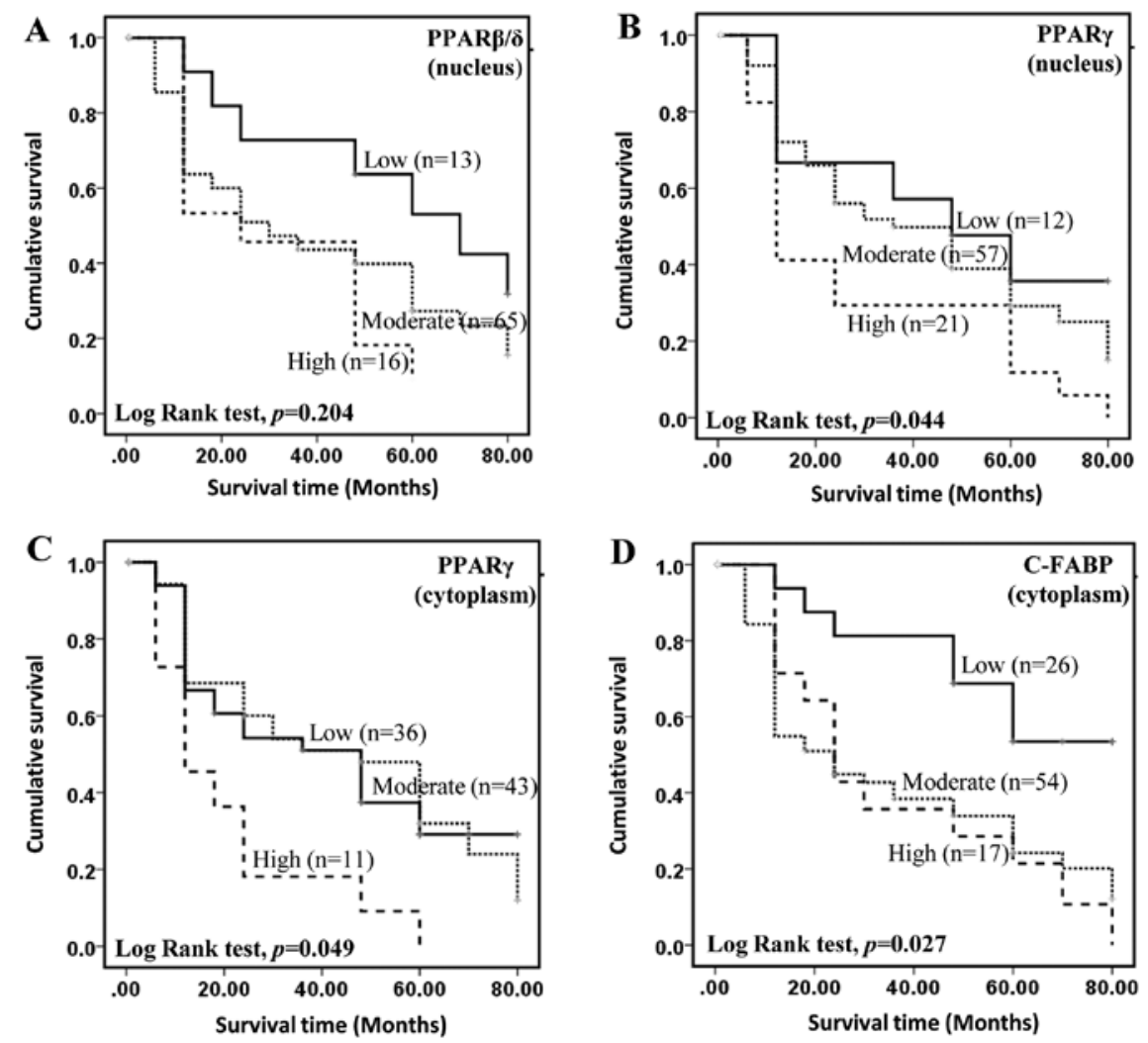

Figure 3. Kaplan-Meier survival curves of prostate cancer patients. The cumulative survival of patients was plotted against time in months for different levels of 4 parameters. (A) Different levels of nuclear staining for PPAR $\beta / \delta$ : weakly positive group $(n=13)$; moderately positive group ( $\mathrm{n}=65)$; and highly positive group $(n=16)$. (B) Different levels of nuclear staining for PPAR $\gamma$ : weakly positive group $(n=12)$; moderately positive group $(n=57)$; and highly positive group $(n=21)$. (C) Different levels of cytoplasmic staining for PPAR $\gamma$ : weakly positive group $(\mathrm{n}=36)$; moderately positive group ( $\mathrm{n}=43$ ); and highly positive group ( $\mathrm{n}=11)$. (D) Different levels of cytoplasmic staining for C-FABP: weakly positive group ( $\mathrm{n}=26)$; moderately positive group ( $\mathrm{n}=54)$; and highly positive group ( $\mathrm{n}=17$ ).

unstained and $2(6 \%)$ stained weakly in the cytoplasm. In the nucleus, $25(71 \%)$ were unstained, $7(20 \%)$ stained weakly, $5(14 \%)$ stained moderately and $3(8 \%)$ stained strongly (Fig. 2I). Among 97 analysed adenocarcinomas, cytoplasmic and nuclear staining was observed in $94(96 \%)$ and $88(91 \%)$ of cases, respectively (Fig. 2J-L). Cytoplasmic staining was weak in 23 (24\%), moderate in $54(56 \%)$ and strong in $17(18 \%)$ cases. In the nucleus, 20 (21\%) cases stained weakly, $32(33 \%)$ moderately and $36(37 \%)$ strongly. Intensities of both cytoplasmic $\left(\chi^{2}\right.$ test, $\left.p<0.001\right)$ and nuclear $\left(\chi^{2}\right.$ test, $\left.p<0.001\right)$ staining for C-FABP were significantly higher in carcinomas than those in BPH (Table II).

Correlations between $C-F A B P, P P A R \beta / \delta, P P A R \gamma$ and $G S$. When the relationship among the staining levels for PPAR $\beta / \delta$, PPAR $\gamma$ and C-FABP in carcinomas was assessed, that increased levels of PPAR $\beta / \delta$ in both cytoplasm and nucleus were not significantly correlated with either staining for PPAR $\gamma$ or C-FABP (Fisher's exact test, $\mathrm{p}>0.05$ ), although cytoplasmic staining for PPAR $\beta / \delta$ was significantly correlated with its nuclear levels $\left(\chi^{2}\right.$ test, $\left.p<0.001\right)$. The increased cytoplasmic level of PPAR $\gamma$ was positively correlated with that in the nucleus $\left(\chi^{2}\right.$ test, $\left.\mathrm{p}<0.001\right)$, and similarly for staining for $\mathrm{C}-\mathrm{FABP}\left(\chi^{2}\right.$ test, $\left.\mathrm{p}<0.05\right)$. While increased nuclear staining for C-FABP was significantly correlated with increased nuclear staining for PPAR $\gamma($ Fisher's exact test, $p<0.05$ ), increased cytoplamic staining for C-FABP was not significantly corre- lated with cytoplasmic staining for PPAR $\gamma\left(\chi^{2}\right.$ test, $\left.\mathrm{p}>0.05\right)$. Interestingly, the increased cytoplasmic staining for C-FABP was significantly correlated with nuclear staining for PPAR $\gamma$ (Fisher's exact test, $\mathrm{p}<0.05$ ), whereas the increased cytoplasmic staining for PPAR $\gamma$ was not significantly correlated with nuclear staining for C-FABP $\left(\chi^{2}\right.$ test, $\left.p>0.05\right)$. To correlate the staining for PPAR $\beta / \delta$ and GS, carcinomas were divided into low ( $\leq 5)$, moderate (6-7) and high (8-10) GS groups. Neither nuclear $\left(\chi^{2}\right.$ test, $\left.p>0.05\right)$ nor cytoplasmic $\left(\chi^{2}\right.$ test, $\mathrm{p}>0.05)$ staining for PPAR $\beta / \delta$ was significantly correlated with increased GS in these cases. When staining for PPAR $\gamma$ was assessed in a similar way, increased nuclear staining for PPAR $\gamma$ was significantly correlated with the increased GS of the carcinomas (Fisher's exact test, $\mathrm{p}=0.05$ ), but the correlation between its cytoplasm staining and the increased GS was not significant (Fisher's exact test, $\mathrm{p}>0.05$ ). When correlation between staining for C-FABP and GS was assessed, increased cytoplasmic staining for C-FABP was significantly correlated with the increased GS of the carcinomas $\left(\chi^{2}\right.$ test, $\left.p<0.05\right)$, but the correlation between its increased nuclear staining and increased GS was not significant $\left(\chi^{2}\right.$ test, $\left.p>0.05\right)$.

PPAR $\beta / \delta$, PPAR $\gamma, C-F A B P$ and patient survival. The level of PPAR $\beta / \delta$, PPAR $\gamma$ or C-FABP and the duration of patients' overall survival time (the length of survival time from initial diagnosis) was plotted using Kaplan-Meier survival curves and the significance of the differences was assessed by log-rank test 

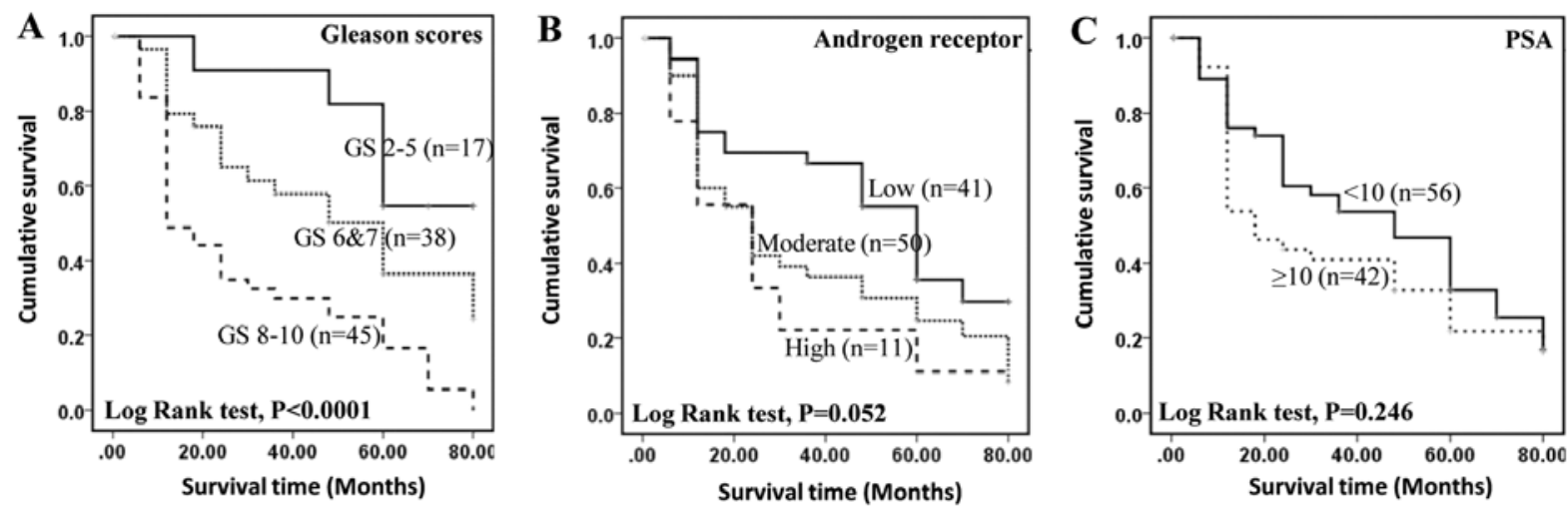

Figure 4. Kaplan-Meier survival curves of patients with prostatic cancer. The cumulative survival of patients was plotted against time in months for different levels of 3 parameters. (A) Different Gleason scores: group 1, GS 2-5 ( $n=17)$; group 2, GS 6-7 ( $n=38)$; group 3, GS 8-10 (n=45). (B) Different AR indices: low group, or AR index 1-3 (n=41); moderate group, or AR index 4-6 ( $\mathrm{n}=50)$ and high group, or AR index 6-9 (n=11). (C) Different levels of PSA: group 1, $\mathrm{PSA}<10 \mathrm{ng} / \mathrm{ml}(\mathrm{n}=38)$ and group $2, \mathrm{PSA} \geq 10 \mathrm{ng} / \mathrm{ml}(\mathrm{n}=64)$.

(Fig. 3). For patients with a strongly positive nuclear staining for PPAR $\beta / \delta$, the median survival time was 24 months (Fig. 3A). Although this was shorter than 30 and 70 months which were the median survival times for moderately and weakly stained cases, respectively, correlation between the level of staining for nuclear and cytoplasmic (data not shown) PPAR $\beta / \delta$ and patient survival time was not significant (log-rank test $\mathrm{p} \geq 0.204)$. When the correlation between nuclear staining for PPAR $\gamma$ (Fig. 3B) and patient survival was assessed, the median survival time for the patients with weak nuclear staining was 48 months, this was reduced to 36 months (log-rank test $\mathrm{p}=0.422$ ) and significantly reduced to 12 months $(\log$-rank test $\mathrm{p}=0.035)$ for patients with moderate and strong staining, respectively. Overall, nuclear staining for PPAR $\gamma$ was significantly associated with patient survival (log-rank test $\mathrm{p}=0.044)$. For cytoplasmic staining for PPAR $\gamma$, although the median survival time for the cases with low staining (48 months) was not significantly (log-rank test $\mathrm{p}=0.995)$ different from those cases with moderate staining (48 months), it was significantly (log-rank test $\mathrm{p}=0.010$ ) reduced to 12 months for cases with strong staining. Similar to nuclear staining for PPAR $\gamma$, overall reduced survival time was significantly associated with the increased cytoplasmic staining for PPAR $\gamma$ (Fig. 3C) (log-rank test, $\mathrm{p}=0.049)$. For the patients with both strong and moderate staining for cytoplasmic C-FABP, the median survival time was 24 months, this was significantly shorter than that of 80 months for patients with weak staining and those unstained (log-rank test, $\mathrm{p}=0.002$ ) (Fig. 3D). While increased cytoplasmic staining for C-FABP was significantly associated with a reduced patient survival time (log-rank test, $\mathrm{p}=0.027$ ) (Fig. 3D), no significant correlation between nuclear C-FABP levels and patient survival time was observed (data not shown).

Patient survival and Gleason scores, androgen receptor and PSA. To assess the relationship between the GS and patient survival, 97 carcinoma cases were divided into three groups: weakly malignant with GS $\leq 5$, moderately malignant with GS 6-7 and highly malignant with GS 8-10. The median survival time of patient with highly, moderately and weakly malignant carcinomas was 12,60 and 80 months, respectively.
The increased GS was significantly (log-rank test $\mathrm{p}=0.0001)$ associated with reduced survival time (Fig. 4A). The correlation between patient survival time and staining for AR showed that the median survival time for patients with weak, moderate and strong staining was 60,24 and 24 months, respectively. Overall survival time was not significantly reduced by the increased staining for AR (log-rank test, $\mathrm{p}=0.052$ ) (Fig. 4B). The correlation between patient survival and blood PSA showed that the median survival time for patients with low $(<10 \mathrm{ng} / \mathrm{ml})$ and high $(\geq 10)$ levels of PSA was 48 and 18 months, respectively (Fig. 4C) but the difference was not statistically significant (log-rank test, $\mathrm{p}=0.246$ ).

Inter-relationship of $C-F A B P$ and $P P A R \gamma$ in predicting patient survival. To assess the possible effect of staining for C-FABP and PPAR $\gamma$ of both cytoplasm and nucleus in associated with patient survival, 90 carcinoma cases were divided into 4 groups: low C-FABP, low PPAR $\gamma$; low C-FABP, high PPAR $\gamma$; high C-FABP, low PPAR $\gamma$; and high C-FABP, high PPAR $\gamma$. For cytoplasmic C-FABP and nuclear PPAR $\gamma$, KaplanMeier plot (Fig. 5A) show that the median survival time for patients with high C-FABP, high PPAR $\gamma$ or high C-FABP, low PPAR $\gamma$ levels (33 and 30 months, respectively) were significantly shorter than whose had low C-FABP, low PPAR $\gamma$ or low C-FABP, high PPAR $\gamma$ levels (60 and 72 months, respectively). Similar results were obtained when dividing up the carcinomas into cytoplasmic staining for C-FABP and cytoplasmic staining for PPAR $\gamma$. Kaplan-Meier plot (Fig. 5B) show that the median survival time for the patient with high C-FABP, high PPAR $\gamma$ or high C-FABP, low PPAR $\gamma$ levels (31 and 39 months, respectively) were significantly shorter than whose had low C-FABP, low PPAR $\gamma$ or low C-FABP, high PPAR $\gamma$ levels (64 and 60 months, respectively). When subjected to Cox's multivariate regression analysis (Table III), staining for cytoplasmic C-FABP still showed a significant association with patient survival $(\mathrm{p}=0.048)$, but increased staining for PPAR $\gamma$ in the nucleus was not significantly independently associated with clinical survival $(\mathrm{p}=0.143)$. Similar results were obtained when analysing cytoplasmic staining for C-FABP and cytoplasmic staining for PPAR $\gamma$ in relation to patient 

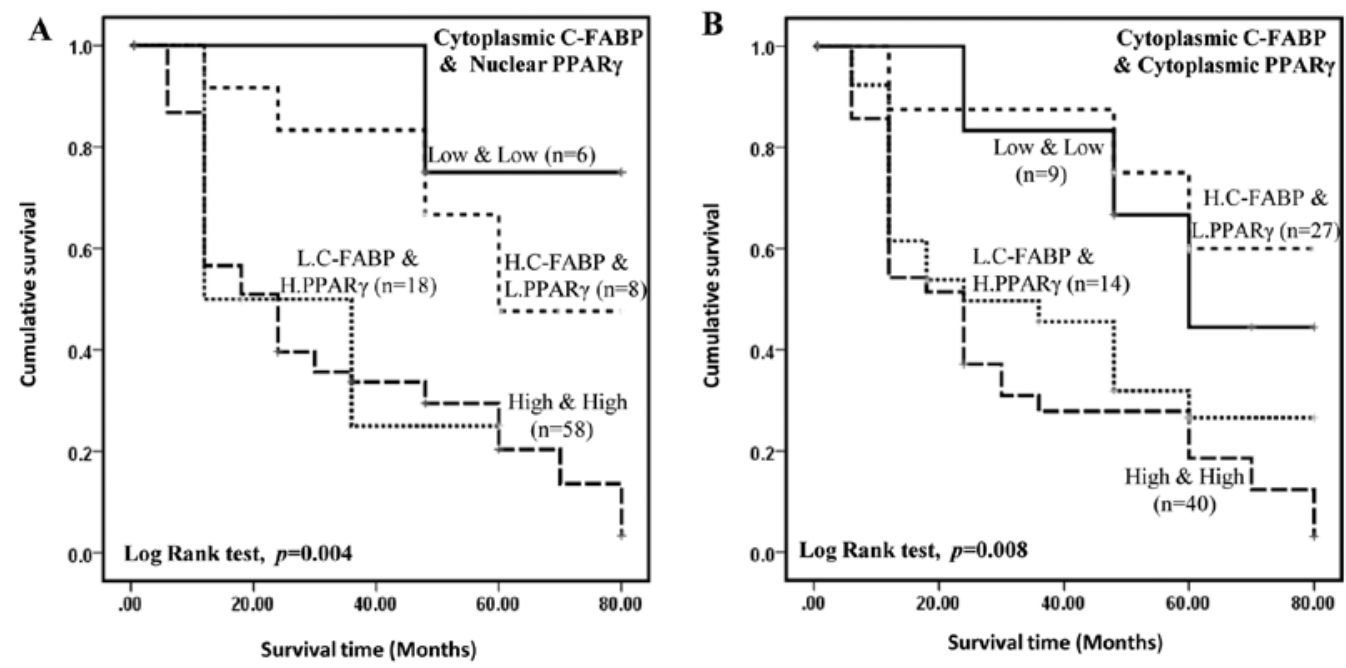

Figure 5. Kaplan-Meier survival curves of patients with prostatic cancer. The cumulative survival of patients was plotted against time in months for different levels of 2 parameters. (A) Different levels of joint nuclear staining for PPAR $\gamma$ and cytoplasmic staining for C-FABP: low C-FABP, low PPAR $\gamma$ group (n=9); low C-FABP, high PPAR $\gamma$ group $(n=14)$; high C-FABP, low PPAR $\gamma$ group $(n=27)$; high C-FABP, high PPAR $\gamma$ group ( $n=40)$. (B) Different levels of joint cytoplasmic staining for PPAR $\gamma$ and cytoplasmic staining for C-FABP: low C-FABP, low PPAR $\gamma$ group $(\mathrm{n}=6)$; low C-FABP, high PPAR $\gamma$ group $(\mathrm{n}=18)$; high C-FABP, low PPAR $\gamma$ group $(n=8)$; high C-FABP, high PPAR $\gamma$ group $(n=58)$.

Table III. Results of multiple Cox regression test between levels of C-FABP, PPARs and patient survival.

\begin{tabular}{lcc}
\hline & $\begin{array}{c}\text { Univariate analysis } \\
\text { (log-rank test) }\end{array}$ & $\begin{array}{c}\text { Multivariate analysis } \\
\text { (Cox regression test) }\end{array}$ \\
\hline $\begin{array}{l}\text { C-FABP } \\
\text { (cytoplasm) }\end{array}$ & $\mathrm{p}=0.027$ & $\mathrm{p}=0.048$ \\
$\begin{array}{l}\text { PPAR } \gamma \\
\text { (nucleus) }\end{array}$ & $\mathrm{p}=0.044$ & $\mathrm{p}=0.143$ \\
$\begin{array}{l}\text { PPAR } \gamma \\
\text { (cytoplasm) }\end{array}$ & $\mathrm{p}=0.059$ & $\mathrm{p}=0.362$ \\
$\begin{array}{l}\text { PPAR } \beta / \delta \\
\text { (nucleus) }\end{array}$ & $\mathrm{p}=0.204$ & \\
\hline
\end{tabular}

survival $(\mathrm{p}=0.362)$. Overall these results show that the significant association of staining for PPAR $\gamma$ with patient survival was confounded by that for staining for C-FABP when tested together. These results suggest that although staining for cytoplasmic C-FABP can be considered as an independent prognostic marker in prostate cancer that for nuclear staining for PPAR $\gamma$ is dependent on staining for cytoplasmic C-FABP. When nuclear staining of C-FABP and nuclear staining of PPAR $\gamma$ was analysed (data not shown), high level of C-FABP and high level of PPAR $\gamma$ was not significantly associated with shorter survival of the patients (log-rank test, $\mathrm{p}=0.195)$.

\section{Discussion}

C-FABP is a $15-\mathrm{kDa}$ cytosolic protein that belongs to the fatty acid binding protein family (3) and binds to long chain fatty acids with high affinity. In addition to skin, C-FABP is detected in endothelial cells of placenta, heart, skeletal muscle, small intestine, renal medulla and in Clara and goblet cells of lung (36). Apart from prostate cancer, $C-F A B P$ has been implicated in malignancies of bladder and pancreas (37-39) and its expression is associated with poor survival in breast cancer (40) and glioblastoma (41). Thus it is possible that large amount of fatty acids transported by elevated levels of C-FABP may generate enhanced signals through their PPAR receptors to cause a chain of molecular events leading to increased activities of cancer-promoting genes and thereby enhance malignant progression $(6,42)$.

There are three nuclear PPARs (PPAR $\alpha$, PPAR $\beta / \delta$ and PPAR $\gamma$ ) that could act as fatty acid receptors (42). Since PPAR $\alpha$ is not expressed in prostate $(18,21)$, it is unlikely to be involved with C-FABP in prostate cancer. Although our data showed that PPAR $\beta / \delta$ is expressed in cultured prostate cells, its level was not demonstrably different between benign and malignant cell lines. However, expression of PPAR $\beta / \delta$ in tissue samples appeared to be different from that in the cell lines. While staining for PPAR $\beta / \delta$ was detected in BPH and carcinoma cases, levels detected in malignant tissues were significantly higher than those in BPH (Table IA). These results suggest that expression of PPAR $\beta / \delta$ in cultured cell lines measured by western blot analysis may not reflect the levels in human tissues measured by immunohistochemical staining. However, increased nuclear staining for PPAR $\beta / \delta$ was not significantly correlated with increased cytoplasmic staining for C-FABP, indicating that elevated PPAR $\beta / \delta$ may not be directly related to C-FABP and hence fatty acid stimulation in prostate cancer cells.

In contrast to the other PPARs, the levels for PPAR $\gamma$, its patterns of expression in cell lines measured by western blot analysis and in tissues measured by immunohistochemistry were very similar to those of C-FABP. Thus the levels of C-FABP and PPAR $\gamma$ in malignant cells were significantly 
higher than those in benign PNT2 cells and elevated levels of PPAR $\gamma$ and C-FABP were associated with increasing malignancy of the prostatic cancer cells (Fig. 1C and E). Similarly in immunohistochemical analysis, the staining levels for PPAR $\gamma$ and C-FABP were significantly higher in carcinomas than in $\mathrm{BPH}$ and the enhanced staining levels in the carcinomas were significantly associated with GS $\left(\chi^{2}\right.$ test, $\mathrm{p}<0.001)$. Furthermore, increased cytoplasmic staining for C-FABP was significantly correlated with increased nuclear staining for PPAR $\gamma$ in the carcinomas. These findings are in line with our separate work, in which we found that C-FABP acted with PPAR $\gamma$ in a coordinated manner to promote malignant progression in prostatic cancer cells (6) and hence, PPAR $\gamma$ is more likely to be the receptor for the fatty acids transported by C-FABP than PPAR $\beta / \delta$. PPAR $\gamma$ and PPAR $\gamma$ ligands inhibit growth and produce terminal differentiation of the human tumor cells (43). PPAR $\gamma$ expression is significant in predicting the outcome of breast carcinomas and is correlated with ER- $\alpha$ status $(44,45)$. PPAR $\gamma$ was found to induce VEGF in colorectal tumor cells $(46,47)$. Thus it was suggested that C-FABP, together with fatty acids, PPAR $\gamma$ and VEGF should be considered as key factors in a proposed fatty acid signaling pathway that promotes metastasis of prostatic cancer cells $(6,11)$. Therefore, the C-FABP-PPAR $\gamma$ axis may be a novel therapeutic target for prostatic cancer.

In prostate cancer management, a major problem is the lack of reliable biomarkers to predict the aggressiveness or potential therapeutic response of an individual prostate cancer. Results in this work suggested that AR (Fig. 4B) and PSA (Fig. 4C) are not significant prognostic markers in our patient group although the number of patients is relatively small. It is also suggested that PSA, the most commonly employed biomarker cannot be used to predict patient outcomes, as previously suggested to be unreliable (48). Our current data show that increased levels of nuclear PPAR $\gamma$ and cytoplasmic C-FABP (Tables IB and II) are significantly correlated with GS (Fisher's exact test, $\mathrm{p}<0.05$ ) and significantly associated with reduced survival time (log-rank test, $\mathrm{p}<0.05)$. These findings suggest that increased levels of nuclear PPAR $\gamma$ and cytoplasmic C-FABP may be alternative objective biomarkers for reduced cellular differentiation (GS), as well as reliable prognostic factors to predict patient survival. Multivariate survival analysis revealed that conjoined cytoplasmic C-FABP and nuclear PPAR $\gamma$ expression may, together, have better prognostic value than when these parameters are used separately. In contrast, no correlation was found between cytoplasmic or nuclear levels of PPAR $\beta / \delta$ and patient survival (Fig. 3A). Increased levels of PPAR $\beta / \delta$ were not significantly associated with increased Gleason scores (Fisher's exact test, $\mathrm{p}>0.05$ ). Therefore, PPAR $\beta / \delta$ was not considered a suitable biomarker to assess the degree of malignancy of a prostate cancer or a marker that would predict patient outcome.

Our results also showed that the level of staining for PPAR $\gamma$ in the cytoplasm was also increased. Although this increase was not correlated with an increased GS, it was significantly associated with a shorter survival time of patients. While the increase of C-FABP in the cytoplasm is significantly associated with GS or patient survival, the increased nuclear C-FABP is not significantly associated with either factor. This suggests that transporting fatty acids to PPAR $\gamma$ through C-FABP may be a short delivery process, after which C-FABP may return to the cytoplasm, rather than staying on the nuclear membrane. More study is therefore needed to find out exactly how the fatty acids are delivered to PPAR $\gamma$ by C-FABP.

As a steroid hormone receptor, activated PPAR $\gamma$ should be theoretically localized in the nuclear membrane. However, many previous studies revealed that the cellular distribution of PPAR $\gamma$ was predominantly cytoplasmic in a number of cancer types (49-52). The reason for the cytoplasmic staining for PPAR $\gamma$ is not known and current opinions on this are inconsistent $(53,54)$. In line with a previous study $(55)$, results in this work showed that the level of PPAR $\gamma$ expressed in the cytoplasm of prostatic carcinoma cells is significantly higher than that in BPH. Furthermore, for cytoplasmic staining, the median survival times for patients with high PPAR $\gamma$ plus low C-FABP, or high C-FABP plus high PPAR $\gamma$ levels were significantly shorter than those who had low C-FABP plus low PPAR $\gamma$ or low C-FABP plus high PPAR $\gamma$ levels (Fig. 5A). More study is needed to understand the biological significance of the increase in cytoplasmic PPAR $\gamma$ and its interaction with $\mathrm{C}-\mathrm{FABP}$ in prostate cancer cells.

This study has extended our previous work to show that co-operation between C-FABP and PPAR $\gamma$ may provide a novel mechanism responsible, in part, for promoting the malignant behavior of human prostate cancer cells and thus supporting our original hypothesis $(6,8,56)$. Such a mechanism would provide a novel opportunity for developing new therapeutic approaches to regulate the malignant phenotype and to switch prostatic cancer cells from an aggressive to indolent behavior, as previously proposed $(57,58)$.

\section{Acknowledgements}

This study was supported by a research project grant from North West Cancer Research. The authors would like to thank Mrs. Carol Beesley, Mrs. Sharon Forest, Mr. Timothy Dickinson, Mrs. Patricia Gerard and Mr. Andrew Dodson for their expert help and support.

\section{References}

1. Ferlay J, Parkin DM and Steliarova-Foucher E: Estimates of cancer incidence and mortality in Europe in 2008. Eur J Cancer 46: 765-781, 2010

2. Lee JT, Lehmann BD, Terrian DM, et al: Targeting prostate cancer based on signal transduction and cell cycle pathways. Cell Cycle 7: 1745-1762, 2008.

3. Madsen P, Rasmussen HH, Leffers H, Honore B and Celis JE: Molecular cloning and expression of a novel keratinocyte protein (psoriasis-associated fatty acid-binding protein [PA-FABP]) that is highly up-regulated in psoriatic skin and that shares similarity to fatty acid-binding proteins. J Invest Dermatol 99: 299-305, 1992.

4. Jing C, Beesley C, Foster CS, et al: Identification of the messenger RNA for human cutaneous fatty acid-binding protein as a metastasis inducer. Cancer Res 60: 2390-2398, 2000.

5. Jing C, Beesley C, Foster CS, et al: Human cutaneous fatty acid-binding protein induces metastasis by up-regulating the expression of vascular endothelial growth factor gene in rat Rama 37 model cells. Cancer Res 61: 4357-4364, 2001.

6. Bao ZZ, Malki MI, Forootan SS, et al: A novel cutaneous fatty acid-binding protein-related signaling pathway leading to malignant progression in prostate cancer cells. Genes Cancer: Sep 18, 2013 (Epub ahead of print). doi: 10.1177/ 1947601913499155. 
7. Adamson J, Morgan EA, Beesley C, et al: High-level expression of cutaneous fatty acid-binding protein in prostatic carcinomas and its effect on tumorigenicity. Oncogene 22: 2739-2749, 2003.

8. Forootan SS, Bao ZZ, Forootan FS, et al: Atelocollagen-delivered siRNA targeting the FABP5 gene as an experimental therapy for prostate cancer in mouse xenografts. Int J Oncol 36: 69-76, 2010.

9. Morgan EA, Forootan SS, Adamson J, et al: Expression of cutaneous fatty acid-binding protein (C-FABP) in prostate cancer: potential prognostic marker and target for tumourigenicity-suppression. Int J Oncol 32: 767-775, 2008.

10. Gebert N, Gebert M, Oeljeklaus S, et al: Dual function of Sdh3 in the respiratory chain and TIM22 protein translocase of the mitochondrial inner membrane. Mol Cell 44: 811-818, 2011.

11. Xu HE, Lambert MH, Montana VG, et al: Molecular recognition of fatty acids by peroxisome proliferator-activated receptors. Mol Cell 3: 397-403, 1999.

12. Santos CR and Schulze A: Lipid metabolism in cancer. FEBS J 279: 2610-2623, 2012.

13. Matsuyama M and Yoshimura R: Peroxisome proliferatoractivated receptor-gamma is a potent target for prevention and treatment in human prostate and testicular cancer. PPAR Res 2008: 249849, 2008.

14. Kliewer SA, Xu HE, Lambert MH and Willson TM: Peroxisome proliferator-activated receptors: from genes to physiology. Rec Prog Horm Res 56: 239-263, 2001.

15. Qi C, Zhu Y and Reddy JK: Peroxisome proliferator-activated receptors, coactivators, and downstream targets. Cell Biochem Biophys 32: 187-204, 2000.

16. Sterchele PF, Sun H, Peterson RE and Vanden Heuvel JP Regulation of peroxisome proliferator-activated receptor-alpha mRNA in rat liver. Arch Biochem Biophys 326: 281-289, 1996.

17. Lemberger T, Saladin R, Vazquez M, et al: Expression of the peroxisome proliferator-activated receptor alpha gene is stimulated by stress and follows a diurnal rhythm. J Biol Chem 271: $1764-1769,1996$

18. Braissant O, Foufelle F, Scotto C, Dauca M and Wahli W: Differential expression of peroxisome proliferator-activated receptors (PPARs): tissue distribution of PPAR-alpha, -beta, and -gamma in the adult rat. Endocrinology 137: 354-366, 1996.

19. Mansure JJ, Nassim R and Kassouf W: Peroxisome proliferatoractivated receptor gamma in bladder cancer: a promising therapeutic target. Cancer Biol Ther 8: 6-15, 2009.

20. Chawla A, Barak Y, Nagy L, Liao D, Tontonoz P and Evans RM: PPAR-gamma dependent and independent effects on macrophage-gene expression in lipid metabolism and inflammation. Nat Med 7: 48-52, 2001

21. Segawa Y, Yoshimura R, Hase T, et al: Expression of peroxisome proliferator-activated receptor (PPAR) in human prostate cancer. Prostate 51: 108-116, 2002.

22. Berthon P, Cussenot O, Hopwood L, Leduc A and Maitland N: Functional expression of sv40 in normal human prostatic epithelial and fibroblastic cells - differentiation pattern of nontumorigenic cell lines. Int J Oncol 6: 333-343, 1995.

23. Cussenot $\mathrm{O}$, Berthon $\mathrm{P}$, Berger $\mathrm{R}$, et al: Immortalization of human adult normal prostatic epithelial cells by liposomes containing large T-SV40 gene. J Urol 146: 881-886, 1991.

24. Horoszewicz JS, Leong SS, Kawinski E, et al: LNCaP model of human prostatic carcinoma. Cancer Res 43: 1809-1818, 1983

25. Stone KR, Mickey DD, Wunderli H, Mickey GH and Paulson DF: Isolation of a human prostate carcinoma cell line (DU 145). Int J Cancer 21: 274-281, 1978.

26. Kaighn ME, Lechner JF, Narayan KS and Jones LW: Prostate carcinoma: tissue culture cell lines. Natl Cancer Inst Monogr pp17-21, 1978.

27. Kozlowski JM, Fidler IJ, Campbell D, Xu ZL, Kaighn ME and Hart IR: Metastatic behavior of human tumor cell lines grown in the nude mouse. Cancer Res 44: 3522-3529, 1984.

28. Forootan SS, Foster CS, Aachi VR, et al: Prognostic significance of osteopontin expression in human prostate cancer. Int J Cancer 118: 2255-2261, 2006

29. Forootan SS, Wong YC, Dodson A, et al: Increased Id-1 expression is significantly associated with poor survival of patients with prostate cancer. Hum Pathol 38: 1321-1329, 2007.

30. Jing C, El-Ghany MA, Beesley C, et al: Tazarotene-induced gene 1 (TIG1) expression in prostate carcinomas and its relationship to tumorigenicity. J Natl Cancer Inst 94: 482-490, 2002.

31. Zhang Y, Forootan SS, Liu D, et al: Increased expression of anterior gradient-2 is significantly associated with poor survival of prostate cancer patients. Prostate Cancer Prostatic Dis 10: 293-300, 2007.
32. Gleason DF and Mellinger GT: Prediction of prognosis for prostatic adenocarcinoma by combined histological grading and clinical staging. J Urol 111: 58-64, 1974.

33. Keller H, Dreyer C, Medin J, Mahfoudi A, Ozato K and Wahli W: Fatty acids and retinoids control lipid metabolism through activation of peroxisome proliferator-activated receptor-retinoid $\mathrm{X}$ receptor heterodimers. Proc Natl Acad Sci USA 90: 2160-2164, 1993.

34. Foster CS, Gosden CM and Ke YQ: Primer: tissue fixation and preservation for optimal molecular analysis of urologic tissues. Nat Clin Pract Urol 3: 268-278, 2006.

35. Remmele W and Stegner HE: Recommendation for uniform definition of an immunoreactive score (IRS) for immunohistochemical estrogen receptor detection (ER-ICA) in breast cancer tissue. Pathologe 8: 138-140, 1987 (In German).

36. Masouye I, Saurat JH and Siegenthaler G: Epidermal fattyacid-binding protein in psoriasis, basal and squamous cell carcinomas: an immunohistological study. Dermatology 192: 208-213, 1996.

37. Celis A, Rasmussen HH, Celis $\mathrm{P}$, et al: Short-term culturing of low-grade superficial bladder transitional cell carcinomas leads to changes in the expression levels of several proteins involved in key cellular activities. Electrophoresis 20: 355-361, 1999.

38. Ostergaard M, Rasmussen HH, Nielsen HV, et al: Proteome profiling of bladder squamous cell carcinomas: identification of markers that define their degree of differentiation. Cancer Res 57: 4111-4117, 1997.

39. Sinha P, Hutter G, Kottgen E, Dietel M, Schadendorf D and Lage $\mathrm{H}$ : Increased expression of epidermal fatty acid binding protein, cofilin, and 14-3-3-sigma (stratifin) detected by two-dimensional gel electrophoresis, mass spectrometry and microsequencing of drug-resistant human adenocarcinoma of the pancreas. Electrophoresis 20: 2952-2960, 1999.

40. Liu RZ, Graham K, Glubrecht DD, Germain DR, Mackey JR and Godbout R: Association of FABP5 expression with poor survival in triple-negative breast cancer: implication for retinoic acid therapy. Am JPathol 178: 997-1008, 2011.

41. Barbus S, Tews B, Karra D, et al: Differential retinoic acid signaling in tumors of long- and short-term glioblastoma survivors. J Natl Cancer Inst 103: 598-606, 2011.

42. Lemberger T, Desvergne B and Wahli W: Peroxisome proliferator-activated receptors: a nuclear receptor signaling pathway in lipid physiology. An Rev Cell Dev Biol 12: 335-363, 1996.

43. Roberts-Thomson SJ: Peroxisome proliferator-activated receptors in tumorigenesis: targets of tumour promotion and treatment. Immunol Cell Biol 78: 436-441, 2000.

44. Jiang Y, Zou L, Zhang C, et al: PPARgamma and Wnt/betacatenin pathway in human breast cancer: expression pattern, molecular interaction and clinical/prognostic correlations. J Cancer Res Clin Oncol 135: 1551-1559, 2009.

45. Papadaki I, Mylona E, Giannopoulou I, Markaki S, Keramopoulos A and Nakopoulou L: PPARgamma expression in breast cancer: clinical value and correlation with ERbeta. Histopathology 46: 37-42, 2005.

46. Rohrl C, Kaindl U, Koneczny I, et al: Peroxisome-proliferatoractivated receptors gamma and beta/delta mediate vascular endothelial growth factor production in colorectal tumor cells. J Cancer Res Clin Oncol 137: 29-39, 2011.

47. Bishop-Bailey D: PPARs and angiogenesis. Biochem Soc Trans 39: 1601-1605, 2011.

48. Roobol MJ, Haese A and Bjartell A: Tumour markers in prostate cancer III: biomarkers in urine. Acta Oncol 50 (Suppl 1): 85-89, 2011.

49. Theocharis S, Giaginis C, Parasi A, et al: Expression of peroxisome proliferator-activated receptor-gamma in colon cancer: correlation with histopathological parameters, cell cycle-related molecules, and patients' survival. Dig Dis Sci 52: 2305-2311, 2007.

50. Han SW, Greene ME, Pitts J, Wada RK and Sidell N: Novel expression and function of peroxisome proliferator-activated receptor gamma (PPARgamma) in human neuroblastoma cells. Clin Cancer Res 7: 98-104, 2001.

51. Zhang GY, Ahmed N, Riley C, et al: Enhanced expression of peroxisome proliferator-activated receptor gamma in epithelial ovarian carcinoma. Br J Cancer 92: 113-119, 2005.

52. Lee TW, Chen GG, Xu H, et al: Differential expression of inducible nitric oxide synthase and peroxisome proliferatoractivated receptor gamma in non-small cell lung carcinoma. Eur J Cancer 39: 1296-1301, 2003. 
53. Jiang WG, Redfern A, Bryce RP and Mansel RE: Peroxisome proliferator activated receptor-gamma (PPAR-gamma) mediates the action of gamma linolenic acid in breast cancer cells. Prostaglandins Leukot Essent Fatty Acids 62: 119-127, 2000.

54. Katagiri Y, Takeda K, Yu ZX, Ferrans VJ, Ozato K and Guroff $\mathrm{G}$ : Modulation of retinoid signalling through NGF-induced nuclear export of NGFI-B. Nat Cell Biol 2: 435-440, 2000.

55. Jiang M, Shappell SB and Hayward SW: Approaches to understanding the importance and clinical implications of peroxisome proliferator-activated receptor gamma (PPARgamma) signaling in prostate cancer. J Cell Biochem 91: 513-527, 2004.
56. Morgan E, Kannan-Thulasiraman P and Noy N: Involvement of Fatty acid binding protein 5 and PPARbeta/delta in prostate cancer cell growth. PPAR Res 2010, Article No. 234629, doi: $10.1155 / 2010 / 234629$

57. Foster CS, Dodson AR, Ambroisine L, et al: Hsp-27 expression at diagnosis predicts poor clinical outcome in prostate cancer independent of ETS-gene rearrangement. Br J Cancer 101: 1137-1144, 2009

58. Yao S, Bee A, Brewer D, et al: $\mathrm{PRKC}-\zeta$ expression promotes the aggressive phenotype of human prostate cancer cells and is a novel target for therapeutic intervention. Genes Cancer 1: 444-464, 2010. 